2 Fontana RS, Sanderson DR, Taylor WF, et al. Early lung cancer detection: results of the initial (prevalence) radiologic and cytologic screening in the Mayo Clinic study. Am Rev Respir Dis 1984; 130:561-5.

3 Fontana RS, Sanderson DR, Woolner LB, et al. Lung cancer screening: the Mayo program. J Occup Med 1986;28:746-50.

4 Marcus PM, Bergstralh EH, Fagerstrom RM, et al. Lung cancer mortality in the Mayo Lung Project: impact of extended follow-up. J Natl Cancer Inst 2000;92:1308-16.

5 Manser RL, Dodd M, Byrnes G, et al. Incidental lung cancers identified at coronial autopsy: implications for overdiagnosis of lung cancer by screening. Respir Med 2005;99:501-7.

6 Henschke Cl, McCauley DI, Yankelevitz DF, et al. Early Lung Cancer Action Project: overall design and findings from baseline screening. Lancet 1999;354:99-105.

7 Swensen SJ, Jett JR, Sloan JA, et al. Screening for lung cancer with low-dose spiral computed tomography. Am J Respir Crit Care Med 2002; 165:508-13.

8 Diederich S, Wormanns D, Semik M et al. Screening for early lung cancer with low-dose spiral CT: prevalence in 817 asymptomatic smokers. Radiology 2002;222:773-81.

9 Pastorino U, Bellomi M, Landoni C, et al. Early lung cancer detection with spiral CT and positron emission tomography in heavy smokers: 2 year results. Lancet 2003;362:593-7.

10 McWilliams A, Mayo J, MacDonald S, et al. Lung cancer screening: a different paradigm. Am J Respir Crit Care Med 2003; 168:1 167-73.

11 MacRedmond R, McVey G, Lee M, et al. Screening for lung cancer using low dose CT scanning: results of 2 year follow up. Thorax 2006:61:54-6.

12 MacRedmond R, Logan PM, Lee $M$, et al. Screening for lung cancer using low dose $C T$ scanning. Thorax 2004;59:237-41.

13 Henschke Cl, Naidich DP, Yankelevitz DF et al. Early lung cancer action project. Initial findings on repeat screenings. Cancer 2001:92:153-9.

14 Swensen SJ, Jett JR, Hartmann TE, et al. Lung cancer screening with CT: Mayo Clinic experience. Radiology 2003;226:756-61.

15 Diederich S, Thomas M, Semik M, et al. Screening for lung cancer with low-dose spiral computed tomography: results of annual follow-up examinations in asymptomatic smokers Eur Radiol 2004;14:691-702.

16 Li F, Sone $\mathrm{S}$, Abe $\mathrm{H}$, et al. Malignant versus benign nodules at $\mathrm{CT}$ screening for lung cancer: comparison of thin-section CT findings. Radiology 2004;233:793-8.

17 Swensen S, Jett JR, Hartmann TE, et al. CT screening for lung cancer: five-year prospective experience. Radiology 2005;235:259-65.

18 Lenox RJ. To screen or not to screen. Ches 2005; 127:1091-2.

19 Wisniveski JP, Mushlin Al, Sicherman N, et al. The cost-effectiveness of low-dose CT screening for lung cancer: preliminary results of baseline screening. Chest 2003; 124:614-21.

20 Manser R, Dalton A, Carter R, et al. Costeffectiveness analysis of screening for lung cancer with low dose spiral CT (computed tomography) in the Australian setting. Lung Cancer 2005;48:171-85.

21 Mahadevia PJ, Fleisher LA, Frick KD, et al. Lung cancer screening with helical computed tomography in older adult smokers. JAMA 2003;289:313-22.

22 National Cancer Institute. National Lung Screening Trial. www.cancer.gov/nlst.

\title{
All change for home oxygen services in England and Wales
}

\section{J A Wedzicha, P M A Calverley}

\section{Changes to the home oxygen service effective from February 2006}

$\Delta$ lthough it was clearly rational to increase the arterial oxygen tension of patients with chronic hypoxaemia, it was not until the publication of two key randomised controlled trials on the effects of long term oxygen therapy (LTOT) in the early $1980 \mathrm{~s}^{12}$ that home oxygen services were developed in many countries where they now form an integral part of the management of chronic respiratory disability. Although these trials addressed the role of oxygen in prolonging life for patients with COPD, three main forms of home oxygen services have developed with rather different goals:

(1) LTOT is prescribed for patients with chronic hypoxaemia $\left(\mathrm{PaO}_{2}\right.$ $\leqslant 7.3 \mathrm{kPa}(55 \mathrm{~mm} \mathrm{Hg})$ ) for continuous use at home and is one of the few interventions to date that has been shown to reduce mortality in patients with COPD.

(2) Ambulatory oxygen therapy refers to the provision of oxygen therapy with a portable device during exercise and daily activities.

(3) Short burst oxygen therapy refers to the intermittent use of oxygen at home, usually provided by stationary cylinders for periods of 10 20 minutes at a time to relieve the symptom of breathlessness. Although short burst oxygen is widely prescribed in the UK for relief of breathlessness, there is little evidence currently available for its benefit ${ }^{3}{ }^{4}$ and delivery of cylinders to the home is costly.

In the UK, provision of LTOT through the prescription of home oxygen concentrators became available in November 1985 and since then concentrators have been installed and maintained by contractors. ${ }^{5}$ Although in Scotland LTOT can be prescribed in secondary care, in England and Wales oxygen concentrators can only be prescribed by primary care physicians. However, this prescription usually takes place on the recommendation of secondary care physicians and concentrators are supplied by a number of contractors on a regional basis. Thus, once patients have been assessed for LTOT in the respiratory clinic, they then have to visit their primary care physician for a prescription for the concentrator.
This process on the whole works efficiently, although there has been some difficulty in communication between primary and secondary care about the nature of the oxygen prescription. ${ }^{6}$ Home oxygen cylinders (usually the larger stationary 1360 litre cylinders) are also prescribed by primary care but are provided by community pharmacists and are mainly used for the provision of short burst oxygen therapy for the relief of breathlessness.

Although oxygen concentrators have been funded by the government in the UK, no formal ambulatory oxygen service has been available. Thus, if a patient requires oxygen for daily activities, this has been provided through small 230 litre cylinders and funded through hospital, charitable or private sources. Liquid oxygen for ambulatory use at home has been difficult to obtain, except on a private basis. It is interesting to speculate on why an ambulatory oxygen service was not organised at the time of the introduction of LTOT in the UK, but the reasons may include lack of good evidence for effectiveness at the time and relatively heavy early equipment for provision of liquid oxygen, $^{7}$ together with the costs of this service. It is also possible that the lack of an organised ambulatory oxygen service has stimulated the excessive prescription of short burst oxygen therapy in the UK.

The failure to provide an ambulatory oxygen service has been an obvious gap in our provision of home oxygen and considerable discussion on this matter has taken place with the Department of Health over the subsequent years. This culminated in a report by the Royal College of Physicians on domiciliary oxygen therapy published in 1999, 
followed by an extensive consultation on the published recommendations. Finally, in June 2003 the Department of Health announced important changes to the provision of oxygen therapy in the home. These changes are currently applicable to England and Wales, although both Scotland and Northern Ireland will review their services and may follow a similar process. The changes apply to both adults and children requiring a home oxygen service and provide an interesting model of how oxygen services can be developed in a state funded healthcare system.

\section{THE NEW SYSTEM}

From February 2006 there will be three main changes to our home oxygen service. Firstly, hospital specialists (usually respiratory physicians) will be able to prescribe home oxygen therapy directly using a special dedicated prescription or home oxygen "order" form that has been developed for use in both primary and secondary care. It is expected that most home oxygen within the new service will be prescribed from secondary care, although primary care physicians will still be able to prescribe if required-for example, for palliative use. Secondly, ambulatory oxygen therapy will now become available on prescription with the provision of various modes of delivery including liquid oxygen, lightweight cylinders, and the use of oxygen conserving devices that can be used with oxygen cylinders to prolong the period of oxygen supply. Other categories of oxygen such as oxygen on an emergency or temporary basis or oxygen provision for holidays within the UK will be much simpler and quicker to obtain. Lastly, all the modalities of oxygen therapy in a given region-oxygen concentrators, equipment for ambulatory oxygen, and short burst therapy-will be supplied by a single contractor and four contractors have been appointed for the 11 oxygen service regions in England and Wales. Each oxygen service region will look to a single contractor to provide all home oxygen needs, making provision and organisation of the service much simpler. As community pharmacists are unable to provide the integrated service required under the new contract, they will no longer play a part in the home oxygen cylinder service.

These changes will also be accompanied by more streamlined oxygen funding streams. Prescribing in primary and secondary care will be funded from Primary Care Trusts (PCTs) unified budgets. PCTs are currently responsible for commissioning health services and they will also be responsible for managing the new oxygen service contracts and the home oxygen service locally. This is a new development which may take some time to settle in and run smoothly.

The objective of ambulatory oxygen is to enable the patient to leave the home for a longer period of time, to improve health status, and to increase daily activities. Ambulatory oxygen has been shown, mainly in relatively short term studies, to be effective in increasing exercise capacity and reducing breathlessness in patients with exercise arterial oxygen desaturation. ${ }^{9-11}$ Thus, patients requiring ambulatory oxygen prescription will either already be on LTOT or they will have a $\mathrm{PaO}_{2}$ above the limit for LTOT prescription but show evidence of exercise desaturation.

Previous studies have shown that many patients taking ambulatory oxygen therapy spend relatively little time outside the home and, surprisingly, do not use their equipment on a regular basis. ${ }^{9}{ }^{12}$ A recent randomised controlled trial of ambulatory oxygen therapy in Canada was terminated early as usage of the ambulatory oxygen in the study was very low. ${ }^{13}$ A significant proportion of patients on LTOT are housebound, being unable to leave the home unaided. ${ }^{6}$ Not all patients in this housebound group will require ambulatory oxygen and portable oxygen use will be required for short periods only. The low use may reflect the nature of the oxygen device provided. Most patients will require a small cylinder, while those patients who need to spend more time outside the home will need an oxygen conserving device with a lightweight cylinder or provision of liquid oxygen. Thus, before prescription of ambulatory oxygen, it is important to determine the level of outside activity that the patient is likely to perform so that the most effective and economical device is provided. Education of the patient in how to use this treatment and what to expect from it is an important part of optimising the use of ambulatory oxygen and should be undertaken by those assessing the patient's suitability for treatment.

The BTS Working Party charged with developing practical guidance for clinicians on assessment of patients for oxygen developed three categories for prescription of ambulatory oxygen:

- Grade 1 oxygen requirements (LTOT low activity): these patients are mainly housebound and/or do not leave the home without assistance and will only need to use an occasional portable cylinder. The oxygen flow rate will be the same as the patient uses for his or her LTOT as these patients will be using oxygen usually when sedentary. The average time of use will be approximately 1 hour per day but may vary with individual patients.

- Grade 2 oxygen requirements (LTOT active group): this category includes patients receiving LTOT who are mobile and need to leave the home on a regular basis. They will require referral to specialist care for full assessment for ambulatory oxygen and this assessment should be performed as suggested in the document for the clinical component for the home oxygen service in England and Wales prepared by the BTS Working Group on Home Oxygen Services (full document can be accessed on www.brit-thoracic.org.uk). This will involve the determination of the oxygen flow rate required to abolish desaturations below 90\% during exercise. At present we have no reliable tools to predict which patients will be compliant users of ambulatory oxygen and thus we suggest that patients are first provided with ambulatory oxygen sufficient for 2 hours use daily and asked to monitor their daily usage. All patients should be seen after 2 months when their true requirement can be determined and the oxygen order adjusted if necessary.

- Grade 3 requirements (non-LTOT patients who are exercise desaturators): these patients will require referral to specialist care for more detailed assessment as to whether they meet the criteria for ambulatory oxygen.

\section{IMPLICATIONS OF NEW SERVICE}

This new service has a number of implications for all respiratory physicians in England and Wales. Most specialists are already performing assessments for LTOT, but relatively few of us have been assessing patients for ambulatory oxygen therapy and assessment services need to be expanded to include these assessments. Appropriate assessment of patients is essential so that the right patients are treated with home oxygen for the right period of time and with appropriate flow rates to obtain optimal benefits and reduce the chance of adverse effects.

Implementation of this new home oxygen service has required identification of the many patients that are being prescribed short burst oxygen therapy for the relief of breathlessness. This has been an onerous task and is still underway. Some patients will be found to be hypoxaemic and then continue with appropriate assessment for LTOT and ambulatory oxygen, while others may be 


\section{EDITORIAL}

identified who are not hypoxaemic but show exercise desaturation and again can be assessed formally for ambulatory oxygen. Hopefully, short burst oxygen can be withdrawn where usage is minimal, as the expectation is that the reduction of costs associated with cylinder delivery for short burst purposes can be used to fund the new ambulatory oxygen service.

These changes to the home oxygen service in England and Wales are radical and overdue; they have been awaited for the past 20 years and should be of enormous benefit to our patients. At last patients will be able to obtain ambulatory oxygen therapy of various types and matched to their daily oxygen needs. The requirement for a new home oxygen service has made us all go back and examine critically the evidence for the benefit of home oxygen in patients with chronic respiratory disability. Although the evidence for LTOT use is good, the case for ambulatory oxygen therapy is much weaker because of the short term studies performed, the relatively poor ambulatory oxygen usage, and the combination of both LTOT and non-LTOT patients together in studies. Since the home oxygen trials published 25 years ago, relatively little research has been performed on one of the most important interventions in respiratory medicine. The new home oxygen service is an ideal opportunity to resurrect some of these unanswered questions which now will be much easier to address.

Thorax 2006;61:7-9.

doi: 10.1136/thx.2005.056192

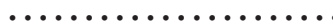

\section{Authors' affiliations}

J A Wedzicha, Royal Free and University College Medical School, University College London, UK

P M A Calverley, University Hospital Aintree, University of Liverpool, Liverpool, UK

Correspondence to: Professor J A Wedzicha, Royal Free and University College Medical School, London NW3 2PF, UK; i.a.wedzicha@ medsch.ucl.ac.uk

Competing interests: JAW and PMAC are both members of the British Thoracic Society Working Party on Home Oxygen Services and have previously been members of the Royal College of Physicians Subcommittee on Domiciliary Oxygen Therapy. The BTS Working Party on Home Oxygen Services has contributed to the clinical guidance that has led to the development of the specification for the Home Oxygen Service.

\section{REFERENCES}

1 Nocturnal Oxygen Therapy Trial Group Continuous or nocturnal oxygen therapy in hypoxaemic chronic obstructive lung disease. Ann Intern Med 1980;93:391-8.
2 Medical Research Council Working Party. Long term domiciliary oxygen therapy in chronic hypoxic cor pulmonale complicating chronic bronchitis and emphysema. Lancet 1981;i:681-6.

3 Smith AA, Crawford A, MacRae KD, et al. Oxygen supplementation before or after submaximal exercise in patients with chronic obstructive pulmonary disease. Thorax 2003;58:670-3.

4 Stevenson NJ, Calverley PMA. Effect of oxygen on recovery from maximal exercise in patients with chronic obstructive pulmonary disease. Thorax 2004;59:668-72.

5 Stretton TB. Provision of long term oxygen therapy. Thorax 1985;40:801-5.

6 Restrick U, Paul EA, Braid GM, et al. Assessment and follow-up of patients prescribed long term oxygen treatment. Thorax 1993:48:708-13.

7 Leggett RJ, Flenley DC. Portable oxygen and exercise tolerance in patients with chronic hypoxic cor pulmonale. BMJ 1977;2:84-6.

8 Royal College of Physicians. Domiciliary oxygen therapy services. clinical guidelines and advice for prescribers. London: Royal College of Physicians, 1999

9 Lock AH, Paul EA, Rudd RM, et al. Portable oxygen therapy: assessment and usage. Respir Med 1991;85:407-12

10 Leach RM, Davidson AC, Chinn S, et al. Portable liquid oxygen and exercise ability in severe respiratory disability. Thorax 1992:47:781-9.

11 Eaton T, Garrett JE, Young P, et al. Ambulatory oxygen improves quality of life of COPD patients: a randomised controlled study. Eur Respir J 2002;20:306-12.

12 Vergeret J, Brambilla C, Mounier L. Portable oxygen therapy; use and benefit in hypoxaemic COPD patients on long term oxygen therapy. Eur Respir J 1989:2:20-5.

13 Lacasse $Y$, Lecours $R$, Pelletier $C$, et al. Randomised trial of ambulatory oxygen in oxygen-dependent COPD. Eur Respir $J$ 2005; 25 : 1032-8.

\section{Paper by Brusasco and colleagues: COPE review}

Further to our notice published in the October 2003 issue of Thorax concerning the paper by Brusasco and colleagues (Brusasco V, Hodder R, Miravitlles M, Korducki L, Towse L, Kesten S: "Health outcomes following treatment for six months with once daily tiotropium compared with twice daily salmeterol in patients with COPD", Thorax 2003;58:399-404), we would like to inform our readers that the review of this paper by the Committee on Publication Ethics (COPE) is now completed. We can confirm that the data reported in the paper are not in question. In this issue we publish a letter from the authors concerning the paper (see page 91).

Wisia Wedzicha, Editor in Chief, Thorax 